\title{
Virtual Reality in Teaching of Foreign Languages
}

\author{
V. Dobrova \\ Samara State Technical University \\ Samara, Russia \\ victoria_dob@mail.ru \\ K. Trubitsin \\ Samara State Technical University \\ Samara, Russia
}

\author{
P. Labzina \\ Samara State Technical University \\ Samara, Russia
}

\author{
N. Ageenko \\ Samara State Technical University \\ Samara, Russia
}

\author{
Yu. Gorbunova \\ Samara State Technical University \\ Samara, Russia
}

\begin{abstract}
Studying the mechanisms of language and speech abilities showed that the most effective method of learning a foreign language is a method of total immersion as students enter the natural language environment and are in it constantly. But the learning process in the classroom, no matter how organized and communicative it is, cannot replace the real experience of teaching. As the most important factors for the effective foreign language learning are the language environment and the motivation, thus the development of new motivational language learning environments, including virtual reality (VR) and 3D environment, are the basic elements of the learning process. The development of VR technology allows expanding the boundaries of science and introducing innovations in all spheres of human activity. In the educational establishments of the USA and China, VR environments are already widely used, but in Russia VR is used only in a few schools and universities. The group of teachers of Samara State Technical University designed the new generation educational course of English based on the VR technology that creates a real situational interaction in which the student can receive certain information, to carry out scientific and educational elements, project activities. In such educational space, VR helps students to understand the phenomena and situations that cannot be understood and explained in the traditional techniques, to become part of the real world through the simulation. In general, VR is an ideal learning environment, and the possibility of its technologies for teaching has an extremely high potential for application.
\end{abstract}

Keywords-virtual reality; teaching; learning environment; foreign language; English course

\section{INTRODUCTION}

The study of the mechanisms of linguistic and speech abilities, processes of speech perception and speech production showed that the most effective method of teaching a foreign language is the full immersion method, since students get into the natural language environment and are constantly in it. As the possibility of living and studying abroad for the majority of those who study a foreign language is not generally available, methodologists and teachers are in constant search of alternative methods of teaching and creating educational models close to the natural language environment. This includes short-term language courses abroad, bilingual education, international projects on academic mobility, and "active learning" techniques, such as business role plays, video, the "immersion" methods, the "real situations" method, cases and so on.

Although such efforts make their contribution to the process of teaching the language, bringing it closer to real life, it is worth noting that they do not bring the desired, ideal result. The process of learning in a class, however organized and communicative, cannot replace the experience of real language learning. Scientists emphasize that the study of a foreign language in textbooks and in the classroom as a whole limits the progress in learning and using the language, which is especially noticeable in such areas as teaching vocabulary, speech, spontaneous speech and intercultural competence [1].

These shortcomings emphasize, on the one hand, the importance of the language environment for effective learning, and on the other hand, the leading role of motivation in the study of language. Accordingly, the development of new motivational environments for language learning, including virtual reality and 3D environments, and the use of meaningful, engaging, culturally and professionally oriented learning materials are the basic and necessary elements of the learning process. The development of virtual reality technologies allows expanding the boundaries of science and introducing innovations into all spheres of human activity.

Information technology as a whole is now a ubiquitous presence in all educational settings as well as places in which people work [2]. In schools in the USA, China and Japan, such virtual technologies and virtual environments are already widely used, and virtual lessons are very popular. In Russia, the technologies of augmented and virtual reality are used only in some schools and universities. So far this is not included in the compulsory education program, but several examples have 
already been realized: thus, the supplemented reality in teaching is applied in the form of adding interactive material to ordinary textbooks. When one points the camera phone or tablet on the picture in the textbook, a student can see, for example, the form of a medieval castle in $3 \mathrm{D}$, and view it from different angles on the screen of the device. One can watch a video of a chemical reaction or even conduct a virtual experiment, mixing virtual chemical elements.

H. Rheingold notes that the problem of higher education today is that approaches to teaching and learning became old and not much effective. He suggests: "rather than lecture halls with rowed seats being the predominant physical learning space for learning and teaching in higher education, learning spaces need to include: physical/virtual, formal/informal, blended, mobile, personal, and professional learning spaces that need to consider flexibility, adaptability, and time. They need to mirror contemporary learning and teaching strategies that emphasize independent and peer-based learning in both physical and virtual learning spaces." [3] In higher education in Russia, virtual reality technologies have been used for several years, although their application is of a single nature.

\section{TERMS “VIRTUAL", "VIRTUALITY”, "VIRTUAL REALITY”}

Originally, the epithet "virtual" (from Latin virtus imaginary) was introduced by specialists in quantum physics to designate ephemeral (unobservable) elementary particles that arise and exist only in the process of interaction of other particles. N.A. Nosov notes that in ancient philosophy and medieval scholasticism the term virtus (virtual) was one of the central categories, denoting a possible, potential, referring to the reality of a different (higher) order [4]. However, then its meaning changed radically: "virtual" began to mean the opposite of material, ephemeral, trying to artificially recreate reality. Subsequently, this concept was used to designate three-dimensional computer macromodels, and then rapidly expanded its terminological boundaries, becoming one of the universal characteristics of information activities as such.

For the first time, the term "Virtual Reality" (VR) was introduced by the computer programmer Ya. Lanier in 1988 and was defined as "a combination of high-speed computers, advanced programming techniques, and interactive devices designed to make computer users feel they have stepped into another world, a world constructed of computer data " [5].

H. Reingold defines VR as an experience in which a person «is surrounded by a three-dimensional computergenerated representation» [6], where it is possible to move around in the virtual world, to see it from different angles, to reach into it, to grab it, to reshape it, thus getting experience. Currently, VR generally describes the technologies of headmounted displays, arm-mounted displays and surround-screen projection-based displays. A head-mounted display consists of a pair of miniature displays positioned in goggles or in a helmet strapped to the user's head so that each eye sees one display. Traditionally, head-mounted displays have been used to provide high-quality stereo visualization of 3D virtual environments. An arm-mounted display or BOOM is like a head-mounted goggle display but is suspended from an articulated arm and is held to the viewer's face with handles.
Surround-screen virtual environments are semi immersive visual displays that are capable of providing very wide-fieldof-view visualization and some of them are even capable of fully covering the human field of view.

S. McGlashan and T. Axling understand by VR «graphical two dimensional or three dimensional interface for interaction between the user and the computer that applies to computersimulated environments that can simulate places in the real world, as well as in imaginary worlds» [7].

Having analyzed the definitions of the concept of "virtuality", proposed by various researchers, one can distinguish its main features:

- $\quad$ relevance: virtual objects exist only up to date, only "here and now";

- $\quad$ autonomy: the laws of the existence of virtual objects do not coincide with the laws of the existence of reality, generating them;

- $\quad$ generation: these objects are produced by the activity of some other reality external to them, and exist only while this activity lasts;

- interactivity: virtual objects can interact with the reality that generates them as ontologically independent of it;

- ephemeral: virtual objects are artificial and changeable;

- $\quad$ non-materiality of impact: not being material, virtual objects can produce effects characteristic of the real;

- fragmentation: the freedom to enter virtual reality and the freedom to exit from ensure the possibility of arbitrary interruption and renewal of its existence.

In pedagogy, "VR" is mainly used as a special information space, where the student can receive certain information, carry out contacts, elements of scientific and educational and project activities.

\section{VR EDUCATIONAL ENVIRONMENT}

Although the application of VR with interactive control capabilities and user focus was originally designed for such areas as healthcare (visualization of surgical operations), architecture (visualization of large-scale design projects), aviation (visualization of flight for training pilots), it can be widely used in teaching due to its universal character and the possibility of user interaction in any three-dimensional world, real or abstract. The virtual world can be a building, a human body, an underwater world, space, a museum, a dinner, etc. VR radically transforms the principle of visualization, creating a semblance of real objects through information modeling. As a result, the student gets almost the same (or stronger) personal experience in visual, auditory, tactile, olfactory perception, in the implementation of actions, as well as in real interaction with similar situations. VR is one of the pinnacle of computerized learning. It achieves "overstimulation" of the sense organs (similar to obtaining real perceptual experience), which is the basis of learning, including intellectual learning. 
Virtual reality offers unique learning and teaching experiences due to its ability to provide real-time threedimensional visualization and afford various types of interactivity within virtual learning environments [8]. Many educators and researchers have pointed out the significance of using VR technology and VR environment for engaging learners in the learning process, and thus VR-based applications and software are ubiquitously used in various educational contexts $[9 ; 10 ; 11 ; 12 ; 13 ; 14 ; 15]$.

Thus, there appeared such concept as the educational environment of VR. It describes everything from 3D animation on a personal computer to simulating entire networks. In the educational space, VR helps students understand phenomena and situations that do not lend themselves to understanding and explanation within the framework of traditional methods, to become part of the real world through simulation.

B. Dalgarno enumerates the following characteristics of the educational environment of VR:

- The environment is modelled using 3D vector geometry, so that objects are represented using $\mathrm{x}, \mathrm{y}$ and $\mathrm{z}$ coordinates describing their shape and position in $3 \mathrm{D}$ space;

- The user's view of the environment is rendered dynamically according to their current position in 3D space, that is, the users can move freely through the environment and their views are updated as they move;

- At least some of the objects within the virtual environment respond to user action, for example, doors might open when approached and information may be displayed when an object is selected;

- Some environments include 3D audio, that is, audio that appears to be emitted from a source at a particular location within the environment [16].

Dalgarno's model can be represented in the following way: (see Fig.1).

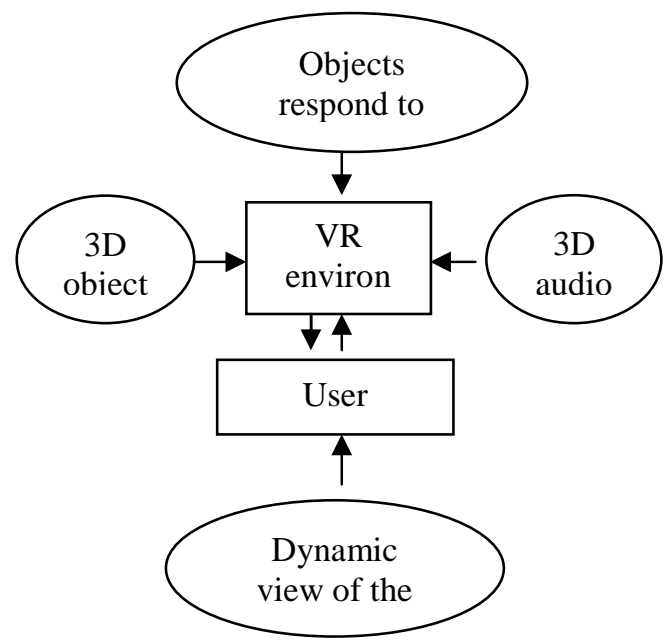

Fig.1. Characteristics of VR learning environment by B.Dalgarno

J. Wann and M. Mon-Williams suggested a different point of view on the educational environment of VR. They believe that the main component of the environment is the ability to interact with the help of direct control: «VR learning environment, therefore, has the potential to provide a powerful interactive simulation of three-dimensional structures in virtual world environments» [17].

Many researchers [18; 19] believe that VR makes it possible to find and operate in environments that are not accessible to people due to time, distance, scale and security.

The authors singled out the following possibilities of VR in education:

1) Visibility. Using 3D-graphics, one can detail the various processes and phenomena $[20 ; 21]$. VR is able not only to provide information about the phenomenon itself, but also to demonstrate it with any degree of detail.

2) Security. Surgical operation on the heart, control of a super-high-speed aircraft, fire - one can immerse the viewer in any of these circumstances without the slightest threat to life.

3) Involvement. VR allows one to change scenarios, influence the course of an experiment, or solve problems in a playable and understandable form. During the virtual lesson, one can see the world of the past through the eyes of a historical character, go on a journey into space, make an ascent to Mount Everest.

4) Focusing. The virtual world, which surrounds the viewer from all sides, will allow concentrating entirely on the material and not being distracted by external stimuli.

5) Presence. A first person view and a sense of one's presence in the painted world is one of the main features of virtual reality. This allows one to conduct lessons entirely in VR.

The teacher of a foreign language can create real situational interaction with the help of VR, for example, such as an interview at employment, the situation in a restaurant, at an airport, etc. Virtual space can vary depending on the objectives, language level, time frame, number of participants, real or animated characters, used devices, etc. It offers students flexible and convenient access that is a key driver for the use of technology in learning [22]. Using VR helps to overcome many difficulties of traditional learning.

\section{NEW GENERATION VR COURSE OF ENGLISH}

The group of teachers and students of Samara State Technical University designed the new generation educational course of English based on the VR technology that creates a real situational interaction in which the student can receive certain information, to carry out contacts, scientific and educational elements and project activities [23]. In such educational space, VR helps students to understand the phenomena and situations that cannot be understood and explained in the traditional techniques, become part of the real world through the simulation.

For the developing of a comprehensive training system in a foreign language using VR technologies "Virtual Customs", 
the concept of three-dimensional modeling of technical systems and processes using software development tools was used, one of which is the Unity3D environment. It should be mentioned that in the software design market of today there are various software development tools each of which has its own advantages and disadvantages [24]. The use of the mentioned concept gives wide possibilities for modeling various scenarios for the functioning of technical systems, both at design stages and during the operation.

To study the aspects of the real object and its linguistic features, a customs point was chosen that is located at the international airport. Students are provided with VR glasses: OculusRift or HTC Vive. Further, the teacher or the student himself launches the training system "Virtual Customs", which should solve the following set of tasks:

- the functioning of the system in two modes: training and interactive with the possibility of testing the student;

- in the training mode, the student makes a virtual inspection of the customs station as a passenger. Then the standard procedure for passing passport and customs control using standard dialogues in a foreign language follows. At the same time, on the screen of the virtual reality device, subtitles of the dialogues of the passenger and the customs personnel are displayed;

- in the interactive mode, the student is offered to undergo another virtual check at the customs office at the airport but in the role of a customs officer.

Thus, the trainee is in the customs zone of the international airport and gets the opportunity to navigate through it, entering into dialogues with the attendants and studying the inscriptions on the customs equipment and stands. To move around the halls, the student uses the LeapMotion tracking device. At the moment, there are two active halls, the so-called "Green Channel" and "Red Channel".

Figure 2 shows the employee of the customs station, who meets the passenger at the entrance. He greets the passenger and tells him about the responsibilities and duties of the customs officer and the customs service.

In the "Green Channel" hall, the passenger can interact with the customs officer, learn the names of the possible goods and types of luggage. To test the learnt materials, the students should participate in the dialogues with missing words, the example of which is shown in Figure 3.

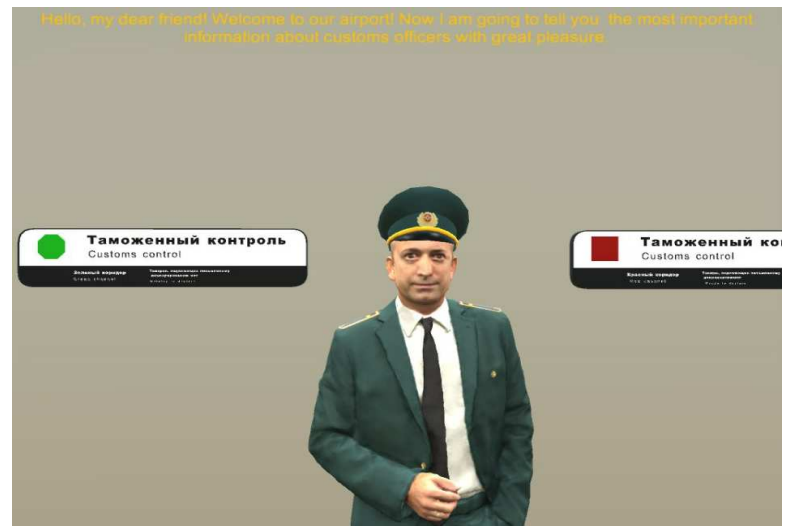

Fig.2. Screen form of the customs officer

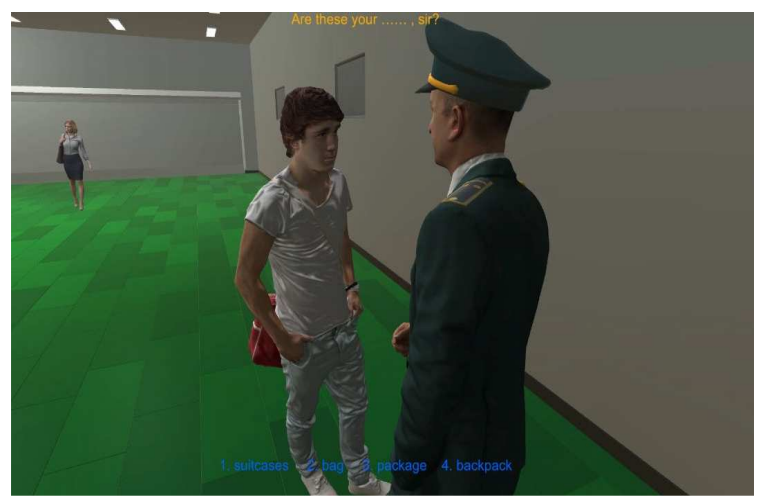

Fig.3. Screen form of the dialogue with missing words

In the "Red Channel" hall, for example, the student can get acquainted with the names of the customs equipment, study the customs declaration, prohibited items list and other documents. For that, it is necessary to proceed to this room and "approach" to the specified objects. Screen forms with examples of described items are shown in Figure 4.

In order to interact with customs personnel through dialogues in a foreign language, it is sufficient for a student to "approach" customs officers who are in each of the halls and differ from passengers of the airport by a form of customs service. The customs officer starts the dialogues which the student can first listen and then participate in it. The customs officer asks the passenger about his baggage, declaration, presence of prohibited items, their price and necessary documentation. He can ask one to open one's suitcase, to put it on the belt, to go back or to arrest one.

To perform the interactive test, the operator must select the necessary training mode. The student is in the customs zone of the international airport already familiar to him. Following it, 


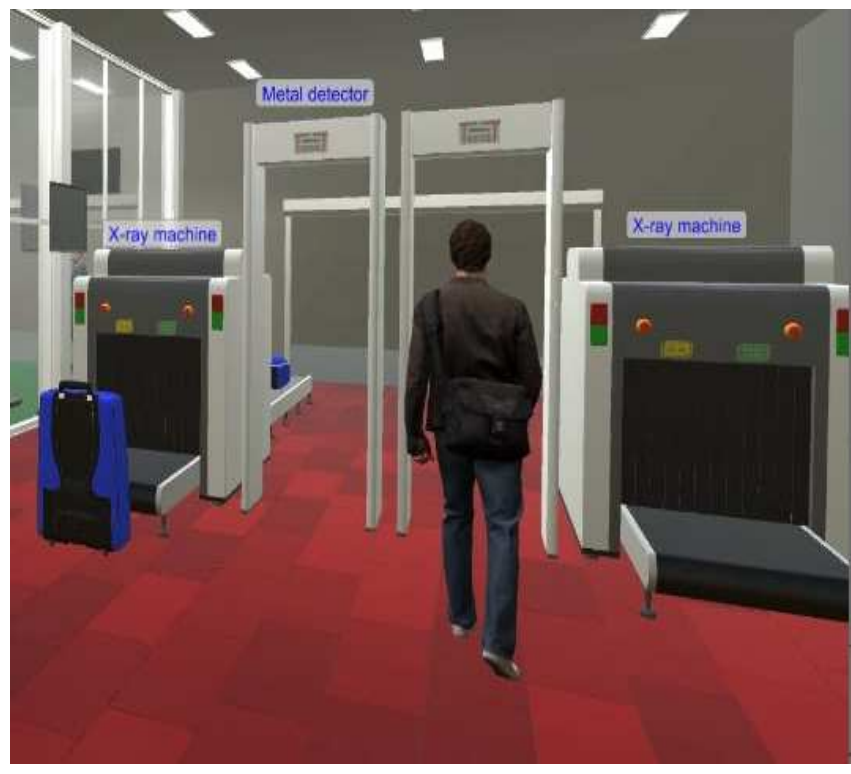

Fig. 4. Screen form of the Red Channel.

the student enters into dialogues with the staff. At the same time, some phrases in the dialogues are skipped and the student is offered to choose the necessary lexeme in accordance with the rules of the foreign language and the semantic load. In this case, the system indicates to the operator and the student the correctness of the chosen answer option. All answers are fixed by the system and on the basis of these data, the training system "Virtual Customs" evaluates the student.

The functional purpose of the integrated learning system in a foreign language with VR technologies "Virtual Customs" is:

- innovative method of teaching a foreign language;

- $\quad$ use of the latest VR technologies in the process of learning a foreign language;

- $\quad$ interactive acquaintance with the customs device on the example of the customs point of the aviation node (international airport);

- $\quad$ preparation of teachers of a foreign language of a higher educational institution for conducting classes with the help of VR technologies on the example of the training system "Virtual customs".

\section{CONCLUSIONS}

It should be mentioned that education, using VR, allows one to visually conduct lectures and seminars, conduct trainings, show the trainees all aspects of a real object or process, which as a whole gives a tremendous effect, improves the quality and speed of educational processes, reducing their cost. VR technologies make it possible to make full use of the information that a person receives from the outside world. At the same time, one should not forget that $80 \%$ of the information a man perceives with the help of vision, as well as the fact that people remember $20 \%$ of what they see, $40 \%$ of what they see and hear, and $70 \%$ of what they see, hear and do.

In general, VR is an ideal learning environment, and the possibilities of its technologies for teaching and research have extremely high potential for application.

\section{References}

[1] J. Milton, "Measuring Second Language Vocabulary Acquisition," Bristol, Multilingual Matters, 342, 2007.

[2] P. Standen, D. Brown, "Mobile learning and games in special education", In: The SAGE handbook of special education. SAGE, London, 2014, pp. 719-730.

[3] H. Rheingold, "Foreword," Physical and Virtual Learning Spaces in Higher Education: Concepts for the Modern Learning Environment. IGI Publishing (IGI Global), Hershey, PA. United States, 2011.

[4] N.A. Nosov, "Virtual psychology," Moscow, Agraph, 2000. (in Russian).

[5] S.M. Grady, "Virtual reality: Simulating and enhancing the world with computers", New York, Facts on file, Inc., 34, 2003.

[6] H. Rheingold, "Virtual Reality", New York, NY, Summit, 56, 1991.

[7] S. McGlashan, T. Axling, "Talking to Agents in Virtual Worlds", Swedish Institute of Computer Science, proc. Of VR-SIG Conf, Sweden, 231, 1996.

[8] J.C. Chwen, Y.L. Siew, S.T. Chee, "A feasible group testing framework for producing usable virtual reality learning applications", Virtual Reality, vol. 19, Iss. 2, pp. 129-144, June 2015.

[9] B. Meredith, C.M. Byrne, "Summer students in virtual reality", Virtual reality: Applications and exploration, pp. 199-218, 1993.

[10] B. Dalgarno, M. Lee, "What are the learning affordances of 3-D virtual environments?", British Journal of Educational Technology, vol. 41.1, pp. 10-32, 2010.

[11] E.G. Doubleday, V.D. O'Loughlin, A.F. Doubleday, "The virtual anatomy laboratory: Usability testing to improve an online learning resource for anatomy education", Anatomical sciences education, vol. 4.6, pp. 318-326, 2011.

[12] C. Freiberg, and Ramasamy-lyer Mahalinga-lyer, "Use of nonimmersive virtual reality in mechanical engineering laboratory," pp. 110, 2005.

[13] V. Ferk, "Students' understanding of molecular structure representations", International Journal of Science Education, vol. 25.10, pp. 1227-1245, 2003.

[14] Z. Merchant, "Effectiveness of virtual reality-based instruction on students' learning outcomes in K-12 and higher education: A metaanalysis", Computers \& Education, vol. 70, pp. 29-40, 2014.

[15] X. Ouyang, , X. Yao, X. Xie, "Design and Implementation of Virtual Lab Based on Internet", Computer Engineering, vol. 2, 2004.

[16] B. Dalgarno, "Characteristics of 3D environments and potential contributions to spatial learning". Doctoral dissertation, University of Wollongong. Retrieved April 18, 2005, from Australian Digital Theses, http://www.library.uow.edu.au/adt-NWU/uploads/approved/adtNWU20050114.092913/public/02Whole.pdf p. 3

[17] J. Wann, and M. Mon-Williams, "What does virtual reality NEED? Human factors issues in the design of three-dimensional computer environments", International Journal of Human-Computer Studies, vol. 44(6), pp. 829-847, 1996.

[18] M. Bricken, "Virtual Reality Learning Environments: Potentials and Challenges", Computer Graphics, vol. 25(3), pp. 178-184, 1991.

[19] J. Cromby, P. Standen, D Brown, "Using Virtual Environments in Special Education", VR in the Schools, vol. 1(3), pp. 1-4, 1995.

[20] So-Y. Yoon, J. Laffey, H. Oh, "Understanding usability and user experience of web-based 3D graphics technology", International Journal of Human-Computer Interaction, vol. 24.3, pp. 288-306, 2008. 
[21] M. K. Stanney, M. Mollaghasemi, L. Reeves, R. Breaux and D.A. Graeber "Usability engineering of virtual environments (VEs): identifying multiple criteria that drive effective VE system design", International Journal of Human-Computer Studies, vol. 58.4, pp. 447-481, 2003.

[22] M. Bower, M.J.W. Lee, B. Dalgarno, "Collaborative learning across physical and virtual worlds: Factors supporting and constraining learner in a blended reality environment", British Journal of Educational Technology, No. 48(2), pp. 407-430, 2017.
[23] V.V. Dobrova, and P.G. Labzina, "Virtual Reality in Teaching Foreign Languages", Vestnik of Samara State Technical University, Psychological and Pedagogical Sciences Series, No. 4 (32), p. 17, 2016.

[24] T. Axling, "Collaborative configuration in virtual environments", Virtual Reality, vol. 3, Iss. 1, pp. 59-70, March 1998. 